\title{
Studies on the effects of soil surface treatments on crop of false morel (Gyromitra esculenta) in spruce forests
}

\author{
RISTO JALKANEN and ESKO JALKANEN
}

\begin{abstract}
JALKANEN, R. \& JALKANEN, E. 1978: Studies on the effects of soil surface treatments on crop of false morel (Gyromitra esculenta) in spruce forests. - Karstenia 18 (suppl.).

These investigations clarify the effects of various soil surface treatment methods on the occurrence of the false morel in spruce forests. The investigations consist of two major series of experiments which both consist of approximately 50 tests.

It has clearly come out that the breaking of the soll surface can increase the produce of false morel, however, the yield has been best on areas where the false morel has occurred naturally before the experiments. The best method of treatment proved to be the breaking of the mineral soil by a $10-20 \mathrm{~cm}$ broad furrow which was made in the tests by a spade. The produce was at it's best over 10 fruit-bodies on a running meter. On the basis of the results the average yield was calculated to be 50-100 kilograms on a hectare in a year, which reduced in money corresponds approximately to the value of the annual growth of the stand in the area. The produce was verified to vary annually, but less than on a ory pine heath.
\end{abstract}

R. Jalkanen, Department of Fonest Pathology, Finnish Forest Research Institute, Unioninkatu 40 A, SF-00170 Helsinki 17, Finland.

E. Jalkanen, Jalkasen puitarha, SF-41400 Lievestuore, Finland.

The false morel (Gyromitra esculenta) is common in conifer and mixed forests in almost all parts of Finland. In spite of its poisonous qualities it is considered a delicacy and is picked up wherever it is found. The average price of the fresh mushroom has for years been about Fmk 10, and in addition it provides valuable tax-free income to pickers. Since the poison can be eliminated by drying or boiling, the mushroom is becoming an export article. This fungus is something typically Finnish and it is offered as a special Finnish delicacy to foreign visitors.

False morel is most common on dry pine heaths, in places where the soil surface is somehow broken. People have always looked for this mushroom in landing places, logging areas and at the brim of sand-pits. Sufficient moisture in the spring has a decisive effect on the development of fruit-bodies and that is why a satisfying yield is obtained only a couple of times in ten years in this area.

It has been observed that false morel grows sporadically also in the poorest spruce forests where the relative humidity is high and spring drought does not prevent the development of fruit-bodies. Besides, there is no sand in the mushrooms growing in spruce forests, which greatly helps their cleaning. These observations made us consider whether it would be possible to increase the number of false morel by manipulating the soil surface in the above areas.

For these various reasons we started to break the soil surface by various methods to learn whether it is possible to affect the initiation of fruit -bodies. Our experiments consist of two series of about 50 tests each. In the former, carried out since 1972, the significance of various soil treatment methods and forms was studied. In the latter, carried out since 1975, the data were extensively applied in several districts in Central and Northern Finland. We have used the word semicultivation to mean the exploitation of uncultivated mycelium at its natural habitat in the forest.

It has been proved that breaking of the soil surface can increase the yield of false morel. The most effective method is a $10-20 \mathrm{~cm}$ broad furrow which exposes the inorganic soil. The furrows were made by spade in our experiments. It was interesting to notice that by taking away only the mossy cover and leaving the litter has no effect on the abundance of fruit-bodies. The effect of soil surface treatment seemed to remain stored, so that the fruit-bodies could arise many years after the stimulation. This occurs when the mycelium has enough energy to produce fruit-bodies.

As many as 10 fruit-bodies could be found per running metre in the best places. There were also many mushrooms in small 20-30 cm deep cavities. However, the number of fruit-bodies varied greatly. Sometimes up to 10 metres of furrow would be empty. The stimulating effect proved to be local because the fruit -bodies found were situated exactly at the spots where the soil surface had been broken. We are not yet certain whether this is due to: 1) the changing ability of one homogenous mycelium to produce fruit -bodies, or 2) separate local occurrences - so called 
clones - which have succeeded in rotting energy for their fruit-bodies to various extents. The latter possibility is more probable on the grounds of some other phenomenon.

The first experiments were made in 1972 and since then there have been false morels in the furrows every year. Two out of those five years have yielded a good crop (1973 and 1974), one mediocre (1977) and two poor (1975 and 1976). Nothing has been done about the furrows after digging them over five years ago but fruit-bodies do appear year after year in them - sometimes exactly in the same places. The litter and the fast spreading moss have covered the furrows, making them almost invisible.

On the basis of these results the average yield was calculated to be 50-100 kilograms per hectare per year, which in terms of money approximately corresponds to the value of the annual growth of the stand in the area. To get 100 kilograms of false morel the distance between two furrows must by 1 metre and the average weight of fruit-bodies $40 \mathrm{~g}$. When the distance is 5 metres, the yield may be $10-20 \mathrm{~kg}$. The furrows can as well be interrupted by obstacles. Shallow cavities 5 metres apart and an area of 0.25 squaremetres may give considerable yields, too. It may be worth mentioning that several mushrooms with an average weight of one kilogramme have been found around old sawdust heaps. The biggest mushroom ever found there weighed $6.15 \mathrm{~kg}$. These discoveries should be an incentive for further research work.

If the furrows are made before August it is possible to harvest mushrooms in the following spring. If the furrows are made later, mushrooms will not appear until two years later.

Although the autumn may be warm and free from snow till Christmas, false morels do not appear then. The situation is different in the spring when the snow begins to melt at the end of April or beginning of May. Small fruit-bodies of $5-20 \mathrm{~mm}$ diametre begin to appear from under the snow. They must have been growing for a few weeks under the snow. Without going into detail we would like to maintain that the variation in day length may regulate the annual growth rhythm of aleo false morel.

Dry weather in the spring limits of course the growth of false morel also in spruce forests. The mushrooms are then smaller and their dry matter is lower. Still, the variation is smaller compared to the conditions on dry heaths. Mushrooms could be expected every year in the spruce forests if there were not other factors.

The false morel seems to be "a quiet loser" that will move away from other rotting mycelia working in the same place. When it once has lost its position, years will pass before it will be equal again and able to produce fruit-bodies. In principle, Finland's valuable natural berries, the arctic bramble (Rubus arcticus) and the cloudberry (Rubus chamaemorus), behave in the same way. They are at their best when the habitat is dominated by them alone. Also false morel is forced to withdraw to poor heaths where there are fewer rotting mushrooms. The mycorrhizae rich in these areas do not seem to disturb the life of false morel noticeably, perhaps not at all.

When the rotting circumstances become difficult, false morel begins to lose its position compared with other rotting mushrooms. For example, in 1974 it rained from the end of June to the end of the year and the total radiation energy was $25 \%$ less than usual. All this meant mushroom failure over wide districts in the springs of 1975 and 1976. The production of our own experiments was 10-20\% of that of the two preceding years. It seems that the mycelium of false morel succeeded in recovering in the summer of 1976 since plenty of fruit-bodies were found in 1977. And what about the future? The summer of 1977 was cold and wet. If the hypothesis is correct, a poor yield is to be expected in wide areas of Finland at least in the spring of 1978. This may again be the case, in the following spring. On the other hand, the more dry and warm summers there are in succession, the better is the yield that can be expected in the following springs. Spring weather will then determine how large the fruit-bodies will grow.

The experiments of the latter test series in Central and Northern Finland were made in 1974 and 1975, which were poor mushroom years in this country. At the moment we do not know if the mycelia - which may be in a poor condition - will at all be able to store the stimulating effect for the years to come. It may prove sensible not to do the stimulating before the second or third warm summer. Obviously we shall know more about these topics in a few years' time. 